\title{
Polysaccharide from Hizikia Fusiformis Enhances the Immunomodulatory Activity of Macrophages
}

\author{
Jieun Lee, $\mathrm{MD}, \mathrm{PhD}^{1}$, Moon Hee Choi, $\mathrm{PhD}^{2}$, Eun-su Jang, $\mathrm{MS}^{2}$, Hyun-Jae Shin, $\mathrm{PhD}^{2}$, and Jung Heon Lee, $\mathrm{PhD}^{2}$ \\ ${ }^{1}$ Department of Otorhinolaryngology Head \& Neck Surgery, Medical College of Chosun University, Gwangju; and \\ ${ }^{2}$ Department of Biochemical and Polymer Engineering, Chosun University, Gwangju, Korea
}

Background and Objectives: Hizikia fusiformis is widely used in oriental health food in Japan, China, and Korea, and is known for its anti-oxidation properties.

Materials and Method: In this study, we investigated the anti-inflammatory and immune-modulatory effects and mechanisms of Hizikia fusiformis ( $H$. fusiformis) extracts in lipopolysaccharide (LPS)-treated RAW 264.7 cells. RAW 264.7 cells were incubated in the presence of different concentrations of the viscozyme component of $H$. fusiformis $(1,2,5$, and $10 \mu \mathrm{g} / \mathrm{mL})$, and changes in expression of pro-inflammatory cytokines (GM-CSF, iNOS, VEGF, and COX-2) were evaluated by real-time PCR and immunoblotting. In addition, the associated signaling pathway including phospho (p)-pNF- $\kappa B$ 65, p-pIkBa, p-p38, and p-p44/42 was also evaluated.

Results: The viscozyme component of $H$. fusiformis downregulated the expression of GM-CSF, iNOS, VEGF, and COX-2 mRNA. The augmented NO and ROS production was decreased by administration of $H$. fusiformis. The signal intensity of p-pNF$\kappa \mathrm{B} 65$, p-pIkBa, p-p38, and p-p44/42 protein activated by LPS was ameliorated by administration of the viscozyme fraction in RAW 264.7 cells.

Conclusion: These results suggest that $H$. fusiformis has potential as a therapeutic agent for inflammatory diseases.

KEY WORDS: Sargassum · Polysaccharides · NF-kappa B · Inflammation · Immunity.

\section{INTRODUCTION}

Immune system has the function to fight against the external antigen or hazardous stimuli for protecting our body and maintaining the homeostasis. Macrophages are one of the component which play a critical role in the innate and adaptive immune responses. The phagocytic activity of activated macrophages would be augmented during inflammation, and they would kill pathogens by the secretion of the pro-inflammatory cytokines, such as tissue necrotic factor (TNF)- $\alpha$, Interleukin (IL)-1 or IL-6, Granulocyte-macrophage colony-stimulating factor (GM-CSF), vascular endothelial growth factor (VEGF) reactive oxygen species (ROS), nitric oxide (NO), and any other mediators like cyclooxygenase (COX)-2, inducible nitric oxide synthase (iNOS), against pathogenic microorganisms to defense the harmful stimuli that cause inflammation. ${ }^{1-4)}$ Activation of macrophages is a key point in innate and adaptive immunities for the initiation and propagation of defensive reactions against pathogens. Thus, the identification of agents that can modulate macrophages is of significant interest.

Hizikia fusiformis (harvey) Okamura (H. fusiformis), a brown sea vegetable growing wild on rocky coastlines around in temperate seaside areas of Korea, Japan, and China. Since it is rich in dietary fiber and essential minerals such as calcium, iron, and magnesium, it has been used as a healthy

Received: November 29, 2018 / Revised: January 25, 2019 / Accepted: February 27, 2019

Address for correspondence: Jieun Lee, MD, PhD, Department of Otorhinolaryngology Head \& Neck Surgery, Medical College of Chosun University, 309 Philmundae-ro, Dong-gu, Gwangju 61542, Korea

Tel: +82-62-220-3200, Fax:+82-62-220-2702, E-mail: jeviolins@gmail.com 
food complement for centuries in East Asian countries. ${ }^{5)}$ Recently, several studies have reported that extract of $H$. fusiformis shows the immune-modulatory, anti-cancer, antiatopic and anti-oxidant activities. ${ }^{6-10)}$

The anti-inflammatory activity of $H$. fusiformis suggests applications for diverse disorders including allergic and auto-immune, and sinonasal relative disease. Allergic disease is immunoglobulin E mediated disease characterized by the hyper-reactivity to environmental allergens that are finally evoked the chronic inflammation in nose, lung or skin etc. which usually treated with antihistamine and intranasal/oral steroids. Many concerns have been reported when used these agents in long-term therapy because of the adverse effects. Since macrophages have an important role in allergic disease, the identification of agents that can modulate the function of macrophages is of significant interest. The potential therapeutic effects of $H$. fusiformis in allergic disease have not been studied. Thus, we evaluated anti-inflammatory mechanisms of the $H$. fusiformis extract using LPS-induced RAW 264.7 cells.

\section{MATERIALS AND METHODS}

\section{Materials}

RAW 264.7 macrophage cell line was purchased from the Korean Cell Line Bank (Seoul, Korea). Neutral red assay kit, 3-(4 5-dimethylthiazol-2-yl)-2 5-diphenyltetrazolium bromide (MTT), lipopolysaccharides (LPS), sulfanilamide, phosporic acid, and naphtyl ethylene-diamine dihydrochloride (NED) were purchased from Sigma Chemical Co. (St. Louis, Missouri, USA). DMEM with the supplement of 100 IU $\mathrm{mL}^{-1}$ benzylpenicillin, $100 \mathrm{IU} \mathrm{mL}^{-1}$ streptomycin was purchased from Gibco (BRL, Gnd Island, NY). The other chemicals and solvents were of analytical reagent grade and purchased from Sigma.

\section{Preparation of Hizikia fusiformis extract}

The natural $H$. fusiformis was extracted and purified in the Department of Biochemical re-engineering in Chosun University. The procedure was similar to the previous work. ${ }^{11)}$ After grinding freeze dried $H$. fusiformis in a mixer, $2 \mathrm{~g}$ of powder was digested and extracted at $50^{\circ} \mathrm{C}$ with $100 \mathrm{uL}$ of viscozyme (in $100 \mathrm{~mL}$ of $0.1 \mathrm{M}$ sodium acetate buffer solution $\mathrm{pH} 4.5$ ) for six hours in a shaking incubator (200 rpm). After digestion, the viscozyme was denatured at $100^{\circ} \mathrm{C}$ for $15 \mathrm{~min}$ and supernatant was harvested with centrifuge $(10,000$ $\mathrm{g}$ for $10 \mathrm{~min})$. The supernatant solution was concentrated in a rotary evaporator and the extract powder was prepared using lyophilizer. The viscozyme component of $H$. fusiformis was used in all experiments.

\section{Cell cultures}

RAW 264.7 macrophage cells were maintained in DMEM media supplemented with $1 \%$ penicillin/streptomycin (gibco/Invitrogen, Carlsbad, CA) and 10\% FBS (Capricorn) (w/ v). The cells were grown to $60 \%$ confluence in $60 \mathrm{~mm}$ culture plates at $37^{\circ} \mathrm{C}$ in a $5 \% \mathrm{CO}_{2}$ humidified atmosphere. Cells were pre-treated with different concentration of viscozyme component of $H$. fusiformis $(1-10 \mu \mathrm{g} / \mathrm{mL})$ for $1 \mathrm{~h}$ and then incubated with LPS (100 ng/mL) for additional $23 \mathrm{~h}$.

\section{Cell viability analysis}

Cell proliferation was measured by a colorimetric assay using MTT. In brief, macrophage RAW 264.7 cells diluted into $5 \times 10^{4}$ cells/well with DMEM medium were seeded in 96-wells plates and cultivated at $37^{\circ} \mathrm{C}$ in an atmosphere of $5 \% \mathrm{CO}_{2}$ for overnight. On next day, the cells were cultured with viscozyme at various concentrations $(1,2,5$ and 10 $\mu \mathrm{g} / \mathrm{mL}$ ) for $23 \mathrm{~h} .10 \mu \mathrm{L}$ of MTT stock solution $(5 \mathrm{mg} / \mathrm{mL})$ were added to each well and incubated for additional $4 \mathrm{~h}$. Blue formazans were eluted from cells by the additional of $100 \mu \mathrm{L}$ of DMSO with gentle shaking for $30 \mathrm{~min}$ at room temperature. The absorbance at $570 \mathrm{~nm}$ was measured by microplate reader (Epoch, BioTek, VT, USA). Cell viability was calculated by the following equation. Cell viability $(\%)=A_{2} / A_{1} \times 100$, where $A_{1}$ is the absorbance of the control group, and $\mathrm{A}_{2}$ is the absorbance of the test samples group. Experiments were performed in triplicate and repeated two times.

\section{Quantitative real-time polymerase chain reaction (qRT-PCR)}

Total RNA was extracted using TRIzol reagent (Invitrogen, Carlsbad, CA) according to manufacturer's instructions. The RNA was reverse transcribed into cDNA with the Reverse Transcription kit (Qiagen, Venlo, NLD). $10 \mu \mathrm{L}$ of SYBR ${ }^{\circledR}$ Green PCR Master Mix (Applied Biosystems, Foster City, CA), 4 pmol of forward /reverse primers each, and $1 \mu \mathrm{L}$ of cDNA in a final volume of $20 \mu \mathrm{L}$ were included in each reaction tube. qRT-PCR was performed using a 7500 FAST qRT-PCR System (Applied Biosystems). Target mRNA expression was normalized to glyceraldehyde-f3- 
phosphate dehydrogenase (GAPDH) expression. Primers used were shown in Table 1. Experiments were repeated more than three times.

\section{Measurement of nitrite oxide}

NO level in the macrophage RAW 264.7 cells was measured as follows. Briefly, RAW 264.7 cells were diluted to a density of $5 \times 10^{5}$ cells/well and incubated for overnight. Various concentrations $(1,2,5$ and $10 \mu \mathrm{g} / \mathrm{mL})$ of viscozyme component of $H$. fusiformis were put into each well for $1 \mathrm{~h}$ and then, LPS (100 ng/mL) was added for additional $23 \mathrm{~h}$. DMEM medium and LPS $(100 \mathrm{ng} / \mathrm{mL})$ were used as a normal control and positive control, respectively. After incubation for $23 \mathrm{~h}$, the culture media was collected and incubated with Griess reagent (5\% phosphoric acid containing $0.1 \%$ NED and $1 \%$ sulfanilamide) for $15 \mathrm{~min}$. NO was assayed at $540 \mathrm{~nm}$ using automated microplate reader (Epoch). Experiments were repeated more than three times.

\section{Phagocytosis assay}

Neutral red uptake method was used to measure the phagocytic capacity of macrophages of $H$. fusiformis. After RAW 264.7 macrophages incubated in a 96 well with $H$. fusiformis for $24 \mathrm{~h}, 200 \mathrm{uL}$ of neutral red solution was added into each well and incubated for another $2 \mathrm{~h}$. After discarding supernatant, the cells were rinsed with fixative fastly and washed with phosphate buffered saline (PBS, pH 7.4) twice to remove the neutral red which wasn't phagocytized by macrophages. Then, cells were lysed by adding $200 \mathrm{uL}$ neutralization solution for lysis for $30 \mathrm{~min}$ at room temperature. The cells were washed with PBS twice, again. Cells treated LPS $(100 \mathrm{ng} / \mathrm{mL})$ were selected as a positive control. The absorbance at $540 \mathrm{~nm}$ was assayed by microplate reader (Epoch).

\begin{tabular}{ll}
\multicolumn{2}{l}{ Table 1. Primers for real-time polymerase chain reaction } \\
\hline \multicolumn{1}{c}{ Primers } \\
\hline iNOS & F: 5'-ACATTGATCAGAAGCTGTCCCAC-3' \\
& R: 5'-CAAAGGCTGTGAGTCCTGCAC -3' \\
GM-CSF & F: 5'-CCTTGACCATGATGGCCAG-3' \\
& R: 5'- TGGAGGGCAGTGCTGTTTG-3' \\
VEGF & F: 5'-CTACCTCCACCATGCCAAGT-3' \\
& R: 5'-GCAGTAGCTGCGCTGATAGA-3' \\
COX-2 & F: 5'-TGTATGCTACCATCTGGCTTCGG-3' \\
& R: 5'-GTTTGGAACAGTCGCTCGTCATC-3' \\
GAPDH & F: 5'-ATCATCCCTGCCTCTACTGG-3' \\
& R: 5'-GTCAGGTCCACCACTGACAC-3' \\
\hline
\end{tabular}

F: forward, R: reverse
Experiments were repeated more than three times.

\section{DCF-HA assay}

Intracellular ROS levels were measured by the 2'7'-dichlorofluorescein diacetate (DCF-DA) assay. After RAW 264.7 macrophages incubated in a 96 well with $H$. fusiformis for $1 \mathrm{~h}$ plus additional $23 \mathrm{~h}$ with LPS treatment, the medium was removed and the cells were washed twice with PBS. Then, the cells were incubated with 5 uL DCF-DA diluted in PBS for $30 \mathrm{~min}$ at room temperature. The $\mathrm{H}_{2} \mathrm{O}_{2}$ was used as a positive control. Fluorescence was measured using a fluorescence plate reader (BMG LABTECH GmbH, Offenberg, Germany). Experiments were repeated more than three times.

\section{Immunoblot analysis}

After $24 \mathrm{~h}$ incubation with LPS $(100 \mathrm{ng} / \mathrm{mL})$, the medium was removed and cells were washed with PBS and lysed with 1\% NP-40 lysis buffer. After centrifuging at $13,000 \times \mathrm{g}$ for $10 \mathrm{~min}$ at $4^{\circ} \mathrm{C}$, the supernatant was collected. Equal amounts of protein were separated by electrophoresis on $10-12 \%$ Tris- $\mathrm{HCl}$ gels and then processed to transfer to a PVDF membrane. After blocking with TBS-T (20 mMTris, $500 \mathrm{nM} \mathrm{NaCl}$, and $0.1 \%$ Tween-20) containing $5 \%(\mathrm{w} / \mathrm{v})$ skim milk, the membrane was incubated with a specific primary antibody for phospho(p)-NF- $\mathrm{B}$ p 65, p-IкB $\alpha$, p-p38,p38, p-p44/42 (Cell Signaling Technology, Danvers, MA, USA) or GAPDH (Santa Cruz Biotechnology) followed by peroxidase-conjugated anti-mouse immunoglobulin $\mathrm{G}$ (IgG) or anti-rabbit IgG (Jackson Immuno Research, West Grove, PA,USA). The membranes were developed using the enhanced chemiluminescent analysis system (ChemiDoc MP, Bio Rad, Hercules, USA). Results were obtained from three independent experiments (p-p44/ 42 , p-p38); and obtained from two independent times ( $p$ pIkBa:p-pNF-kB 65) .

\section{Statistical analysis}

All experimental data were presented as mean \pm standard deviation (SD). It was analyzed by Mann-Whitney U test using SPSS (version 20.0, IBM Corp., Armonk, NY, USA). The difference was considered to be statistically significant at a level of $\mathrm{p}<0.05$. 


\section{RESULTS}

\section{Effect of $H$. fusiformis on the cell viability of RAW} 264.7 cells

RAW 264.7 cells viability in the presence of $H$. fusiformis is shown in Fig. 1. As shown in figure, the viability of RAW 264.7 cells did not decrease significantly with the increase of polysaccharide concentrations from $1 \mathrm{ug} / \mathrm{mL}$ to $100 \mathrm{ug} /$ $\mathrm{mL}$, the results indicate that viscozyme extract of $\mathrm{H}$. fusiformis does not affect the viability of RAW 264.7 cells at the concentration of $1-100 \mathrm{ug} / \mathrm{mL}$.

\section{Effect of $\boldsymbol{H}$. fusiformis on the phagocytic activity of RAW 264.7 cells}

As shown in Fig. 2, phagocytic activity of $H$. fusiformistreated RAW 264. 7 cells all exceeded the control group and with the increase of the concentration of $H$. fusiformis, the phagocytosis of macrophage RAW 264.7 cells was significantly increased in a dose-dependent manner, which indicated that $H$. fusiformis had abilities to enhanced phagocytic activity of RAW 264.7 cells. The phagocytic activity at the concentrations of $1-10 \mathrm{ug} / \mathrm{mL}$ of $H$. fusiformis extract was significantly higher than the control group $(\mathrm{p}<0.05)$.

\section{Effect of $H$. fusiformis on the production of NO}

To evaluate the effects of $H$. fusiformis on the production of NO in RAW 264.7 cells, Griess assay was performed to determine the nitrite accumulation. LPS $(100 \mathrm{ng} / \mathrm{mL})$ was

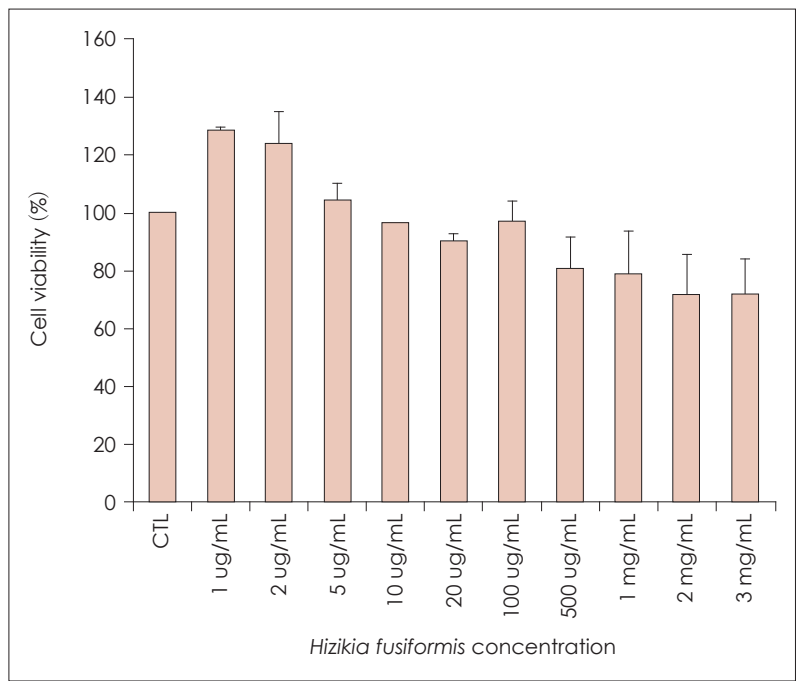

Fig. 1. Effect of $H$. fusiformis on the viability of RAW 264.7 cells. H. fusiformis extract per se did not affect the viability of airway epithelial cells until the concentration of $100 \mathrm{ug} / \mathrm{mL}$. More than the concentration, the viability was slightly decreased. used as a positive control. As shown in Fig. 3A, NO production of macrophage RAW 264.7 cells was increased after treatment with LPS $(100 \mathrm{ng} / \mathrm{mL})$. The increased NO production was decreased with the $H$. fusiformis treatment in a dose-dependent manner. It had statistical significance in high concentration $(\mathrm{p}<0.05)$.

\section{Effect of $H$. fusiformis on the production of ROS}

DCF-DA can be used for detection the intracellular ROS due to oxidative stress, since it can react with radicals and then converted to a fluorescent product. As shown in the Fig. 3B, ROS level was increased in response to the $\mathrm{H}_{2} \mathrm{O}_{2}$ and LPS treatment (positive control). Compared to positive control group, the ROS level was decreased in H. fusiformis pre-treated group. However, it did not reach to the statistical significance.

\section{Effect of $H$. fusiformis on the various mRNAs expression}

In terms of pro-inflammatory cytokines such as iNOS, GM-CSF, VEGF and COX-2, the mRNA expression was augmented by the LPS treatment. The augmented iNOS mRNA expressions were decreased significantly after $H$. fusiformis pre-treatment from at a concentration. The elevated levels of GM-CSF and VEGF mRNA by LPS treatment were significantly decreased by the high concentration of $H$. fusiformis ( $<0.05$ ) (Fig. 4). However, there was

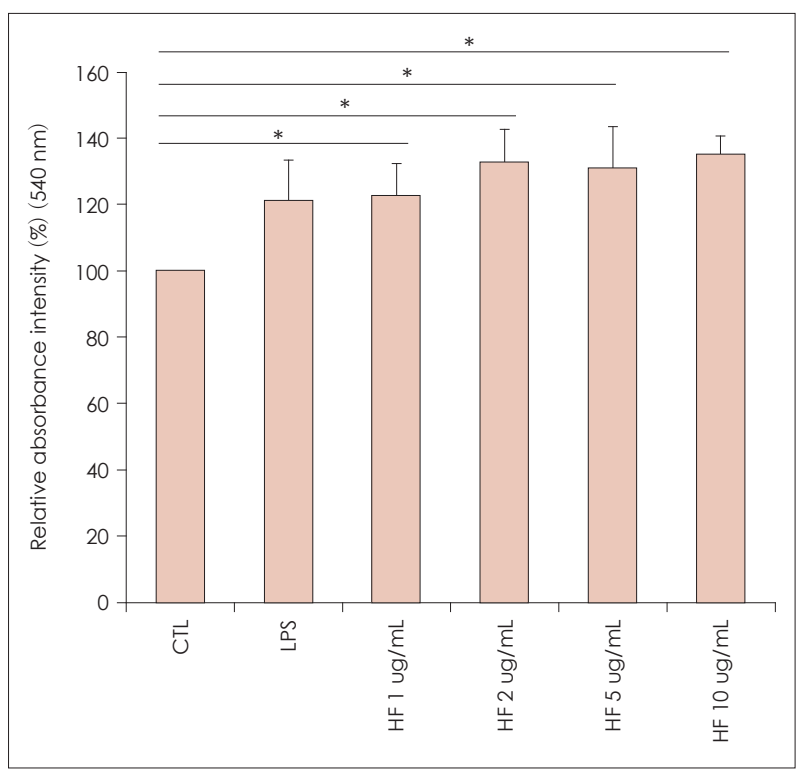

Fig. 2. Effect of $H$. fusiformison the phagocytic activity of RAW 264.7 cells. Phagocytic activity of macrophage RAW 264.7cells was significantly increased in a dose-dependent manner $(p<0.05)$. HF: Hizikia Fusiformis, LPS: lipopolysaccharides. 

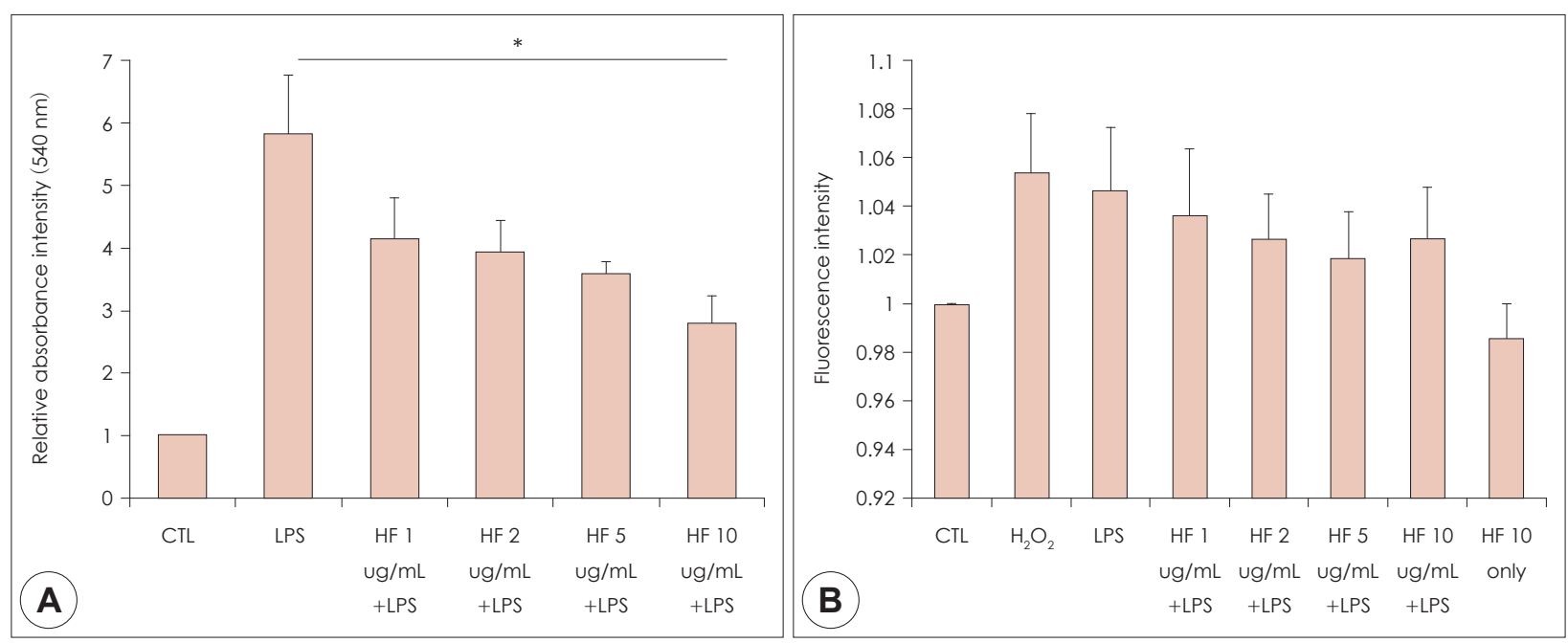

Fig. 3. Effect of $H$. fusiformis on the NO \& ROS production in RAW 264.7 cells. A: RAW 264.7cells were treated with various concentrations of $\mathrm{H}$. fusiformis for $1 \mathrm{~h}$ and LPS for $24 \mathrm{~h}$. Nitrite concentration in the supernatant was detected by Griess reagent, and NO production was measured by absorbance at $540 \mathrm{~nm}$. LPS $(100 \mathrm{ng} / \mathrm{mL})$ was used as the positive control. Values are expressed as the mean \pm SD $(n=3, p<0.05)$. B: Compared to positive control group, ROS level was decreased in H. fusiformis pre-treated group. NO: nitric oxide, ROS: reactive oxygen species, HF: Hiziki fusiformis, LPS: lipopolysaccharides.

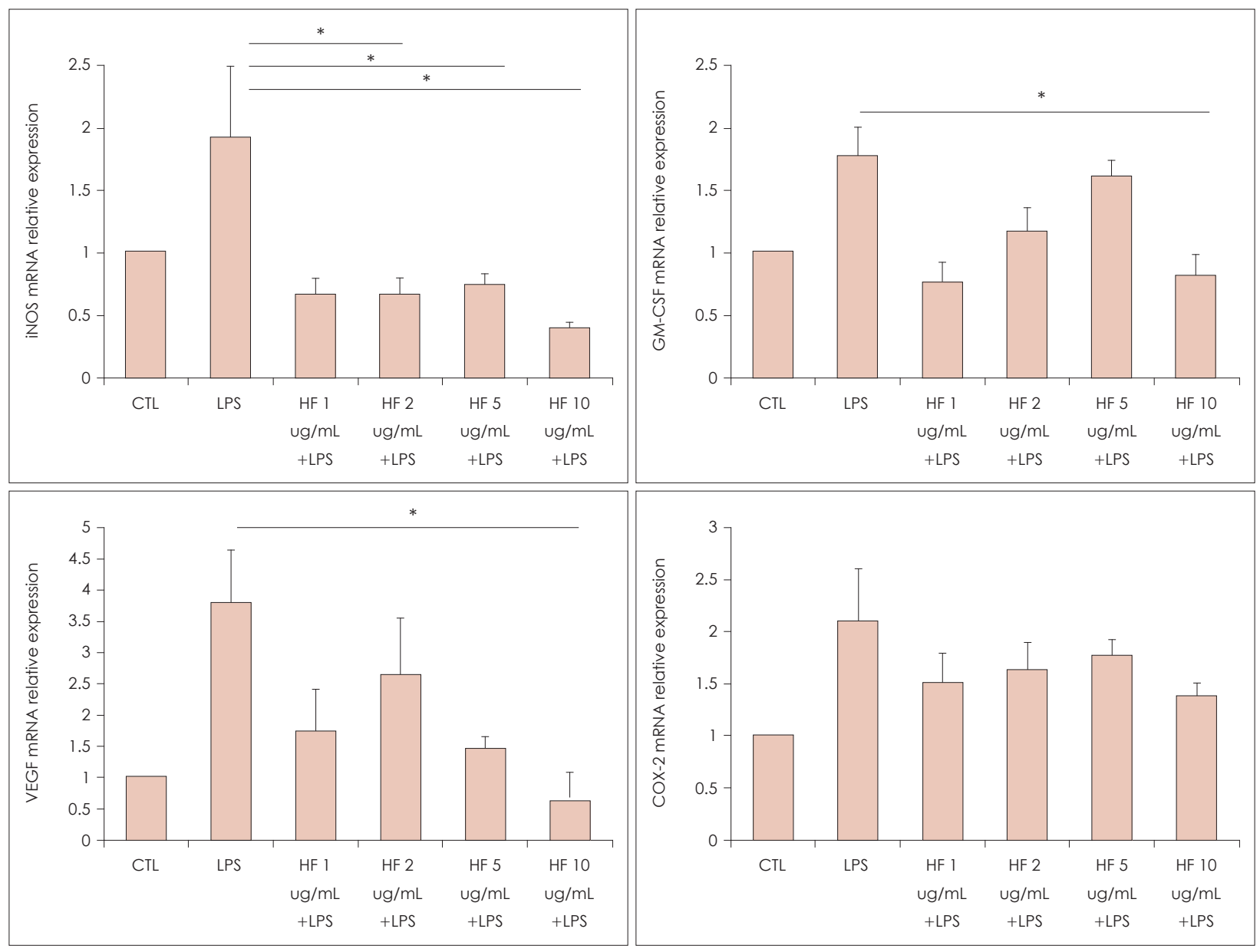

Fig. 4. Effect of $H$. fusiformis on the various mRNA expression. The augmented iNOS mRNA expressions by LPS administration were decreased significantly after $\mathrm{H}$. fusiformis pre-treatment. The elevated levels of GM-CSF and VEGF mRNA by LPS treatment were significantly decreased by H. fusiformis (HF: $10 \mathrm{ug} / \mathrm{mL}$ ) (p<0.05). HF: Hiziki fusiformis, LPS: lipopolysaccharides. 


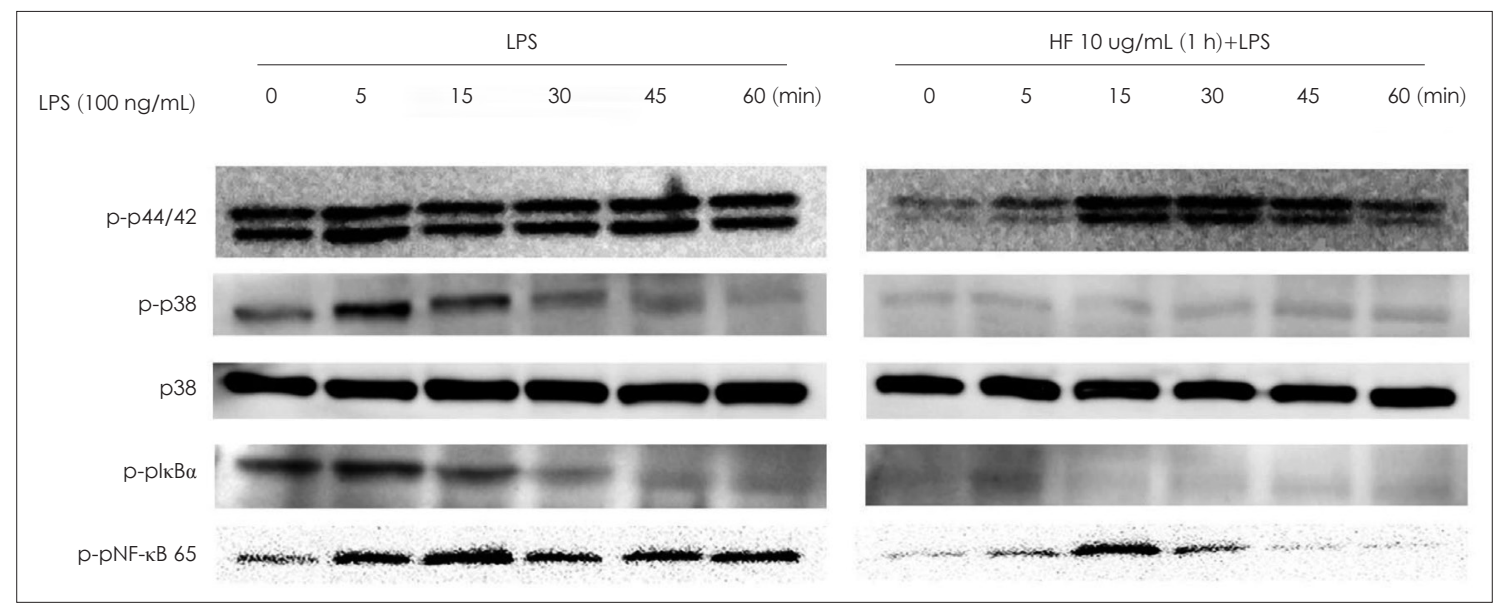

Fig. 5. Anti-inflammatory effect of $H$. fusiformis on the MAPK and the NF-kB pathway. The expression of $p-p 44 / 42$ and $p-p 38$ protein were markedly increased by the treatment of LPS in RAW 264.7 cells, however, pre-treatment of the $10 \mathrm{ug} / \mathrm{mL}$ of $\mathrm{H}$. fusiformis de-

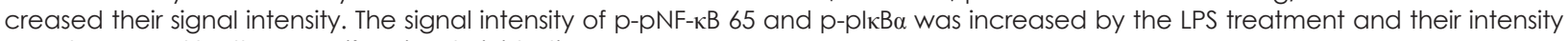
was decreased by the H. Fusiformis administration.

no detectable change in COX-2 mRNA expression.

\section{Effect of $H$. fusiformis on the ERK, MAP kinase and NF-KB cell signaling pathway.}

The expression of p-p44/42 and p-p38 protein were markedly increased by the treatment of LPS in RAW 264.7 cells, however, pre-treatment of the $10 \mathrm{ug} / \mathrm{mL}$ of $H$. fusiformis decreased their signal intensity. As for NF- $\kappa \mathrm{B}$ cell signaling pathway, the signal intensity of p-pNF- $\mathrm{B} 65$ and p-pI $\mathrm{B} \alpha$ was increased by the LPS treatment and their intensity was decreased by the $H$. fusiformis administration (Fig. 5).

\section{DISCUSSION}

H. fusiformis are widely consumed in Japan for centuries, however, it had not been yet developed any kind of healthrelated commercial product. Since, plant-derived natural product have priority over the medication, several efforts to find out the bioactive material from nature product are still ongoing. Until now, fucoidan and laminarin are known to be the major constituents of $H$. fusiformis with published bioactive effects. ${ }^{12)}$ Here, we reported the anti-inflammatory and anti-oxidant effect of $H$. fusiformis extract. In this study, results showed that $H$. fusiformis could improve immune function by enhancing the phagocytic activity of macrophage and down-regulating the pro-inflammatory cytokine mRNA expressions. Also, LPS-activated MAPK and NF$\kappa \mathrm{B}$ signal pathway were also de-activated by the administration of the viscozyme component of $H$. fusiformis.

Macrophage play a significant defensive role in immuni- ty. They have the ability of phagocytosis of parasites and microbes and to activation process of T-and B-lymphocyte by antigen. ${ }^{13)}$ Phagocytosis of pathogens not only participates in activating the innate and adaptive immune system, but also in the regulation of immune regulation, thus, one could escape from foreign invasion by using this mechanism and improve the organism's immune function. Present study showed that $H$. fusiformis significantly enhanced the phagocytosis activity of the macrophage RAW264.7 cells (Fig. 2). This results suggest that $H$. fusiformis has the potential to be developed as an immune booster or immuno-potentiator.

Macrophages are also an important source of pro-inflammatory cytokine (TNF, IL-1, IL-6, IL-12), VEGF, NO and chemokines, leukotrienes, prostaglandins, and complement, which are the main effectors in the inflammatory process. ${ }^{13)}$ TNF and GM-CSF can stimulate human macrophage to kill some microbes. iNOS produced by macrophage produce NO by oxidation of L-arginine, which act as a cytotoxin. The generated NO also contributed to kill the infectious microorganism, ${ }^{14)}$ and increased iNOS protein and NO level have been found in chronic inflammatory or autoimmune disease, such as asthma, rheumatoid arthritis and diabetes. ${ }^{15-17)}$ In this study, H. fusiformis extract has proved to down regulate their expression. These finding are consistent with the previous studies results. ${ }^{12}$ Hence, given that allergic disease has a background of several kinds of chronic inflammation, this iNOS/NO reducing potential of $H$. fusiformis extract would might have a clinical importance. Moreover, NO has the potential as cell signaling mediator and it has been seen to activate NF- $\mathrm{KB}$ and AP-1 transcription factors, ${ }^{18) 19}$ the 
ability of reducing $\mathrm{NO}$ of $H$. fusiformis is of useful in that many inflammatory mechanisms are related with those transcription factors. In this experiment, other cytokines such as IL-1B, IL-8 and TNF were also evaluated, however, consistent aRT-PCR results had failed to get. And, while previous study had shown that $H$. fusiformis reduce the COX-2 protein expression, ${ }^{20)}$ the reduced level of COX-2 mRNA expression by administration of $H$. fusiformis could not show the statistical significance in our study. This difference might have originated from and related to the preparation process the H. fusiformis.

ROS is generated under not only physiological but also pathological condition and related with many age-related, neurodegenerative, cardiovascular and allergic disease. ${ }^{21)}$ Antioxidant can scavenge the toxic ROS and have beneficial health effect via protecting against some type of disease like cancers and coronary heart disease. ${ }^{22)}$ Any naturally available anti-oxidative compounds are welcomed in daily dietry food. In present study, ROS level was decreased by the administration of the $H$. fusiformis. $\mathrm{H}_{2} \mathrm{O}_{2}$ is a product derived of normal metabolism and converted to singlet oxygen which can oxidize others. ${ }^{23)}$ The activity of $H$. fusiformis observed in the present study implies that it has antioxidants potential to decrease the pro-oxidants like $\mathrm{H}_{2} \mathrm{O}_{2}$, and further study are needed to draw a clear conclusion.

$\mathrm{NF}-\mathrm{kB}$ is a key inflammatory transcription factor that regulates the expression of genes encoding inflammatory cytokines and modulators during inflammation. It forms a cytoplasmic complex under normal physiological conditions, but when activated by LPS, it is released from the inactive complex and translocated into the nucleus to activate different pro-inflammatory target genes, such as iNOS and COX$2 .{ }^{24)}$ Since MAPKs regulate NF- $\mathrm{KB}$ transcriptional activity by phosphorylation of its I $\mathrm{I} \mathrm{B} \alpha$ subunit and mediate cell signal transduction from the cell surface to the nucleus, ${ }^{2526)}$ we measured its effect on MAPKs, such as JNK and p38 activation in RAW 264.7 cells.

In summary, H. fusiformis could markedly improve the immune-modulatory activity of macrophage RAW 264.7 cells by stimulating the phagocytic activity of macrophages and significantly ameliorating the production of NO/ROS in macrophage. Also, H. fusiformis improve immunomodulatory activity through decreasing mRNA levels of pro-inflammatory cytokines (iNOS, GM-CSF and VEGF). The underlying mechanisms of $H$. fusiformis on the regulation of immune response on activating RAW 264.7 may be me- diated by the $\mathrm{p} 38, \mathrm{p} 44 / 42$ and NF-kB signaling pathway. Taken together, H. fusiformis has the potential to be an immuno-modulating agent, and also can be used as functional food and pharmaceutical therapy ingredients.

\section{Acknowledgments}

This research was financially supported by the Ministry of Trade, Industry and Energy (MOTIE) and Korea Institute for Advancement of Technology (KIAT) through the Research and Development for Regional Industry (No. R0006329) and by Basic Science Research Program through the National Research Foundation of Korea (NRF) funded by the Ministry of Science, ICT \& Future Planning (NRF-2017R1 C1B5017429).

\section{Declaration of Interests}

The authors declare that there is no conflict of interest.

\section{Author Contributions}

Moon Hee Choi: acquisition of data, Eun-su Jang: acquisition of data, Hyun-Jae Shin: study concept and design, Jung Heon Lee: study concept and design, Jieun Lee: acquisition of data, analysis and interpretation of data, drafting of the manuscript, revision of the manuscript, statistical analysis, study supervision.

\section{REFERENCES}

1) Lee KY, Jeon YJ. Macrophage activation by polysaccharide isolated from Astragalus membranaceus. Int Immunopharmacol 2005;5: 1225-33.

2) Martinez-Pomares L, Gordon S. Antigen presentation the macrophage way. Cell 2007;131:641-3.

3) Wang Z, Xie J, Yang Y, Zhang F, Wang S, Wu T, et al. Sulfated Cyclocary apaliurus polysaccharides markedly attenuates inflammation and oxidative damage in lipopolysaccharide-treated macrophage cells and mice. Sci Rep 2017;7:40402.

4) Kim MS, Kim SH. Inhibitory effect of astragal in on expression of lipopolysaccharide-induced inflammatory mediators through NF$\kappa \mathrm{B}$ in macrophages. Arch Pharm Res 2011;34:2101-7.

5) Wu M, Wu Y, Qu M, Li W, Yan X. Evaluation of antioxidant activities of water-soluble polysaccharides from brown alga Hizikia fusiformis. Int J Biol Macromol 2013;56:28-33.

6) Shan BE, Yoshida Y, Kuroda E, Yamashita U. Immunomodulating activity of seaweed extract on human lymphocytes in vitro. Int Immunopharmacol 1999;21:59-70.

7) Huh GW, Lee DY, In SJ, Lee DG, Park SY, Yi TH, et al. Fucosterols from Hizikia fusiformis and their proliferation activities on osteosarcoma-derived cell MG63. J Korean Soc Appl Biol Chem 2012; 55:551-5.

8) Lee KH, Kim HJ, Kim HB, Kim ST, Choi YR, Seo DW, et al. Hizikia fusiformis fractions successfully improve atopic dermatitis indices in anti-CD3-stimulated splenocytes and 2,4-dinitrochlorobenzenetreated BALB/c mice. J Pharm Pharmacol 2014;66:466-76.

9) Yang EJ, Moon JY, Kim MJ, Kim DS, Kim CS, Lee WJ, et al. Inhibitory effect of Jeju endemic seaweeds on the production of proinflammatory mediators in mouse macrophage cell line RAW 
264.7. J Zhejiang Univ Sci B 2010;11:315-22.

10) Kang CH, Kang SH, Boo SH, Pak SY, Choi YH, Moon DO, et al. Ethyl alcohol extract of Hizikia fusiforme induces caspase-dependent apoptosis in human leukemia U937 cells by generation of reactive oxygen species. Trop J Pharm Res 2011;10:739-46.

11) Kim HW, Lee JH. Production and Characterization of $\beta$-Glucan Type Oligomer Produced with Enzymatic Hydrolysis of Capsosiphon fulvescens. KSBB Journal 2013;28:151-6.

12) Siriwardhana N, Jeon YJ, Kim SH, Ha JH, Heo SJ, Lee KW. Enzymatic hydrolysis for effective extraction of antioxidative compounds from Hizikia fusiformis. Algae 2004;19:59-68.

13) Arango Duque G, Descoteaux A. Macrophage Cytokines: Involvement in Immunity and Infectious Diseases. Front Immunol 2014;5: 491.

14) Denis M. Tumor necrosis factor and granulocyte macrophage-colony stimulating factor stimulate human macrophages to restrict growth of virulent Mycobacterium avium and to kill avirulent M. avium: killing effector mechanism depends on the generation of reactive nitrogen intermediates. J Leukoc Biol 1991;49:380-7.

15) Hamid Q, Springall DR, Riveros-Moreno V, Chanez P, Howarth P, Redington A, et al. Induction of nitric oxide synthase in asthma. Lancet 1993;342:1510-3.

16) McInnes IB, Leung BP, Field M, Wei XQ, Huang FP, Sturrock RD, et al. Production of nitric oxide in the synovial membrane of rheumatoid and osteoarthritis patients. J Exp Med 1996;184:1519-24.

17) Kröncke KD, Kolb-Bachofen V, Berschick B, Burkart V, Kolb H. Activated macrophages kill pancreatic syngeneic islet cells via arginine-dependent nitric oxide generation. Biochem Biophys Res Commun 1991;175;752-8.
18) Lander HM, Sehajpal P, Levine DM, Novogrodsky A. Activation of human peripheral blood mononuclear cells by nitric oxide-generating compounds. J Immunol 1993;150:1509-6.

19) Pilz RB, Suhasini M, Idriss S, Meinkoth JL, Boss GR. Nitric oxide and cGMP analogs activate transcription from AP-1-responsive promoters in mammalian cells. FASEB J 1995;9:552-8.

20) Sharma BR, Park CS, Ma SJ, Rhyu DY. Anti-inflammatory effects and mechanisms of Hizikia fusiformis via multicellular signaling pathways in lipopolysaccharide-induced RAW 264.7 cells. Pak J Pharm Sci 2017;30:43-8.

21) Fridovich I. Superoxide radical and superoxide dismutases. Annual Review Biochemistry 1995;64:97-112.

22) Hotta H, Nagano S, Ueda M, Tsujino Y, Koyama J, Osakai T. Higher radical scavenging activities of polyphenolic antioxidants can be ascribed to chemical reactions following their oxidation. Biochim Biophys Acta 2002;1572:123-32.

23) Czochra MP, Widensk A. Spectrophotometric determination of hydrogen peroxide scavenging activity. Journal Anlitica Chemica Acta 2002;452:177-84.

24) Isaraf DA, Khaizurin TA, Syahida A, Lajis NH, Khozirah S. Cardamonin inhibits COX and iNOS expression via inhibition of p65NF-

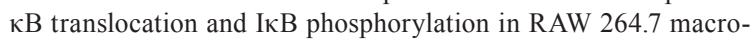
phage cells. Mol Immunol 2007;44:673-9.

25) Kaminska B. MAPK signaling pathways as molecular targets for anti-inflammatory therapy-from molecular mechanisms to therapeutic benefits. Biochim Biophys Acta 2005;1754:253-62.

26) Hoesel B, Schmid JA. The complexity of NF-kB signaling in inflammation and cancer. Mol Cancer 2013;12:86. 